\title{
EXTRACTION, PURIFICATION AND AMYLOSE CONTENT OF SOME STARCHES
}

The amylose content largely determines the behavior of starches during heating and cooking. In processing starchy foods, it is necessary to know the composition of the starches to modify their structure and thus obtain processed products of desirable characteristics and qualities.

The starch content of some Puerto Rican starchy vegetables was reported by Axtmayer and Cook, 1 but the amylose component was not given. Rasper and Coursey ${ }^{2}$ determined the chemical composition of starch extracted from various yam varieties grown in West Africa. Similar information on the chemical composition of the starches extracted from crops grown in Puerto Rico has not been reported previously. To that purpose, the amylose content of extracted starches was determined as part of the studies conducted by the Station to develop products from locally grown, starchy crops.

The starches were extracted by the method described by Cowie and Greenwood, ${ }^{3}$ with the following modifications:

1-Vegetables which darkened after peeling were left under water to reduce browning by avoiding contamination of the extracted starches with the browning pigment.

2-The starch was passed through a 200-mesh sieve to reduce the fiber content.

3-The extracted starch was washed with ethyl alcohol to remove the pigments.

The purified starch was analyzed for ash, protein, fiber content, and $\mathrm{pH}$ to ascertain the efficiency of the purification procedure. It was then fractioned according to the method outlined by McCready and Hassid to obtain pure amylose, which then was used to prepare standard curves for the iodine absorption analyses. Amylose was determined by the method recommended by McCready and Hassid. This method was selected because it is the most generally employed and lends itself to a rapid analysis with a reasonable degree of accuracy.

1 Axtmayer, J. H. and Cook, D. H., Manual de Bromatología, Oficina Sanitaria Panamericana, Publ. No. 186, Washington, D.C., 1942.

2 Rasper, V. and Coursey, D. C., Properties of starches of some West African yams, J. Sci. Fd. Agr. 18: 240, 1967.

s Cowie, J. M. G., and Greenwood, C. T., Physicochemical studies on starches, J. Am. Chem. Soc., III: 2,862-66, 1957.

- McCready, R. M. and Hassid, W. Z., The separation and quantitative estimation of amylose and amylopectin in potato starch, J.Am. Chem. Soc. 65: 1,154-57, 1943. 
The following tabulation shows the amylose content of the starches of several starchy vegetables, analyzed by the iodine absorption method.

\section{Starch source}

Breadfruit (Artocarpus communis)

Green Banana (Musa sapientum)

Green plantain (Musa paradisiaca)

Habanero yam (Dioscorea rolundata)

Tanier (purple variety) (Xanthosoma sp.)

Tanier (white variety) (Xanthosoma sp.)
Amylose conient Percent

25

25

27

34

33

47

M. L. Berrios

M. A. González

Food Technology Laboratory 